\title{
Improving the Krnovo wind power plant efficiency by means of the lithium-ion battery storage system
}

\author{
Filip DRINČIÍ, Saša MUJOVIĆ, Martin ĆALASAN, Lazar NIKITOVIĆ
}

Faculty of Electrical Engineering University of Montenegro

\begin{abstract}
Unpredictable wind nature highly affects wind power plants operation and their capability for an electrical energy production. The Krnovo wind power plant, as a new renewable energy source in Montenegrin power system, is faced with this issue. The utilization of an electrical energy storage system (EES) is proposed in this paper as a way for the problem overcoming. Through performed simulation in MATLAB Simulink software, it was concluded that connection of lithium-ion battery to the wind plant will significantly improve its efficiency. The results of simulations proves the capability of the lithium-ion battery system to maintain the value of Krnovo output power stable, making this facility a more constant power source.
\end{abstract}

\section{Introduction}

Due to the growing environmental pollution caused by the operation of the conventional electricity sources (mostly because of their negative influence on the atmosphere), renewable energy sources are gaining in importance. Wind power plants, as one of the fastest growing renewable energy sources, use free and inexhaustible wind energy to generate electricity. However, despite of their positive sides, as source of electricity that does not pollute the environment, when synchronizing with the electrical power system, their negative sides have to be considered: their inconsistent and unpredictable production can adversely affect the quality of the electrical energy (slower and faster voltage variations, voltage imbalance, frequency variations, occurrence of voltage flickers and harmonics, inefficiency). Variable output power of the wind power plants can also have a negative impact on the stability and reliability of the power system, and if it is connected to a weak power grid, its unsteadiness and uncertainty can cause a complete collapse of voltage. 
The problems caused by connecting wind power plants to the system are not just related to the fact that the generated power changes, but for the fact that a number of variations differs from hour to hour, and that it is difficult to predict. The unpredictability of the production of a wind power plant limits their maximum participation in the production of an electricity system, and requires an increase in reserves in the system. Large variations in generated power create a problem in production planning, affecting voltage variations and stability, both by wind power plants and by the power system. The list of a very common problems related to wind power plants operation is given in Table 1.1.

Table 1.1. Possible negative impacts of the wind power plant on the power system

\begin{tabular}{|c|c|}
\hline Cause & Problem \\
\hline Wind impacts & Impacts of the high current \\
\hline Wind speed variations & Occurrence of voltage flicker \\
\hline Turning on / off the wind turbine & Occurrence of voltage flicker \\
\hline Generator switching current & Voltage drop \\
\hline Power converters & Occurrence of voltage harmonics \\
\hline
\end{tabular}

Wind speed can not be controlled, but we can control the wind power generated energy, thus its efficiency and constantinity, using electrical energy storage (EES) systems. EES transform electricity into another form of energy and use it when it is most needed for the power system.

EES play a very important role in eliminating the disadvantages of renewable energy sources, making them more efficient and more usable, through several important applications: grid stabilization, frequency regulation, transmission loss reduction, load leveling, peak shaving, capacity firming, power quality management etc. For the wind power plants, the most important type of application is capacity firming - ability of the EES to maintain the changeable output from renewable sources at a commited (firm) level for a certain period of time. Large wind power plant needs a huge EES and a good control system to firm its output and make it more consinsent, more predictable and more suitable for the power system. EES can control fluctuations of output active power and adjust reactive power.

The lithium-ion battery, as an EES with the best performance in several categories (self discharge, efficiency, charging time, capacity) is the most favourable solution for integration with wind power plants, because of its high energy density, fast voltage response, and long lifetime expectancy. This paper is based on the simulation of the control of the output power of the Krnovo wind power plant, using a lithium-ion battery, in order to increase its efficiency and role in the power system of Montenegro.

The remainder of the paper is organised as follows: In the next section (Section 2), the basic characteristics of the Krnovo wind power plant, its influence on the network, and the way of its connection to the power system are presented. The above 
data will serve as a basis for a later simulation in MATLAB Simulink software. Section 3 describes the basic principle of the operation of the lithium-ion battery, the method of connection to the system, its advantages and disadvantages. The characteristics that make this battery recommended for integration with the wind power plants are described. Section 4 offers an overview and analysis of the simulation of the connection of the lithium-ion battery to the wind power plant Krnovo, providing adequate graphical explanations. Conclusion and literature are given at the end of the paper.

\section{The Krnovo wind power plant}

The Krnovo wind facility was put into operation in early July 2017., and it is currently the only Montenegrin wind power plant: with a total power of $72 \mathrm{MW}$, and a planned annual output of $200 \mathrm{GWh}$, which is, according to estimates, sufficient to power about 50000 households [1].

Krnovo consists of 26 asynchronous doubly-fed induction generators (DFIG), with rated power of $2.85 \mathrm{MW}$ and $2.5 \mathrm{MW}(20 \times 2.85 \mathrm{MW}+6 \times 2.5 \mathrm{MW})$. Wind generators are located at an altitude around $1500 \mathrm{~m}$, with average wind speed around 5.5 to $6.5 \mathrm{~m} / \mathrm{s}$. The simplified scheme of the Krnovo wind facility is presented in Fig. 2.1. [1].

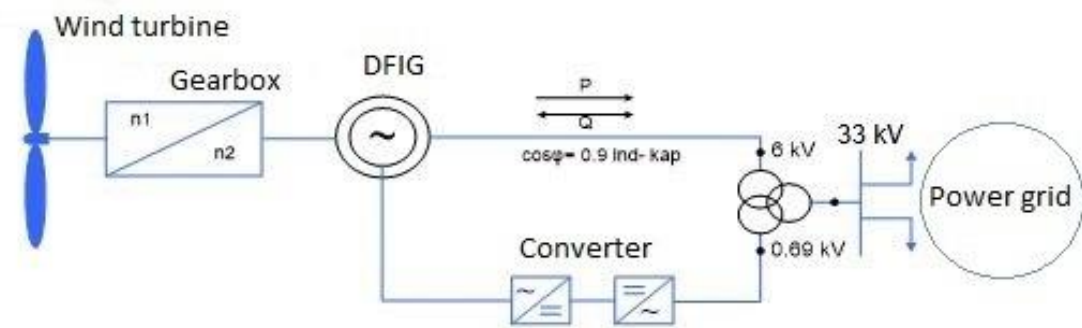

Fig. 2.1. Scheme of the "Krnovo" wind power plant [1]

Wind power plant can have different negative impacts on the power system, depending on the type of the wind turbine. There are two types of wind turbines: with variable and with constant rotational speed, or with the ability to adjust to wind speed changes or without that ability. In the case of wind turbines with the constant speed, the variations of produced power are directly transferred to the power system, which can cause voltage fluctuations and occurrence of voltage flickers in the power system. For the wind turbines with the variable speed, the variations are not directly transferred to the system, due to the power electronic devices which can neutralize the appearance of voltage flickers, but can cause the appearance of voltage harmonics. Using appropriate filters their impact can also 
be neutralized. Wind turbines on Krnovo belongs to group of turbines with ability of adjusting to the wind variations.

According to the results from the Elaborate on testing and compliance of the operation of the Krnovo, it was confirmed that all parameters concerning power quality are within the prescribed limits (voltage variations in normal operation, voltage asymmetry, power factor, voltage harmonic value), except flicker emission factors, which has occasionally appeared in values higher than allowed. However, according to the Elaborate, their impact on the network is insignificant [1]. These results are expected for this type of wind turbine. However, we can not influence on weather conditions and the forecast can not be credibly established for a longer period of time. The inability to own these informations, or the inability to plan the use of the exact amount of power from the wind power plant for a longer period, limits their efficiency and role in the power system.

By analyzing the Fig. 2.2., Fig. 2.3. and Fig. 2.4. obtained on the basis of the results of Krnovo wind power plant tests, it can be concluded that variations of the output power may pose a problem for its efficient use in the Montenegrin power system.

As it is mentioned above, average wind speed at Krnovo area is 5.5-6.5 m/s. Fig. 2.2. and 2.3. represents typical situations on a case of one day with little wind (lower than the average), and day with much wind (higher than the average), while Fig. 2.4. represents the total production of the Krnovo during the trial period of work [1].

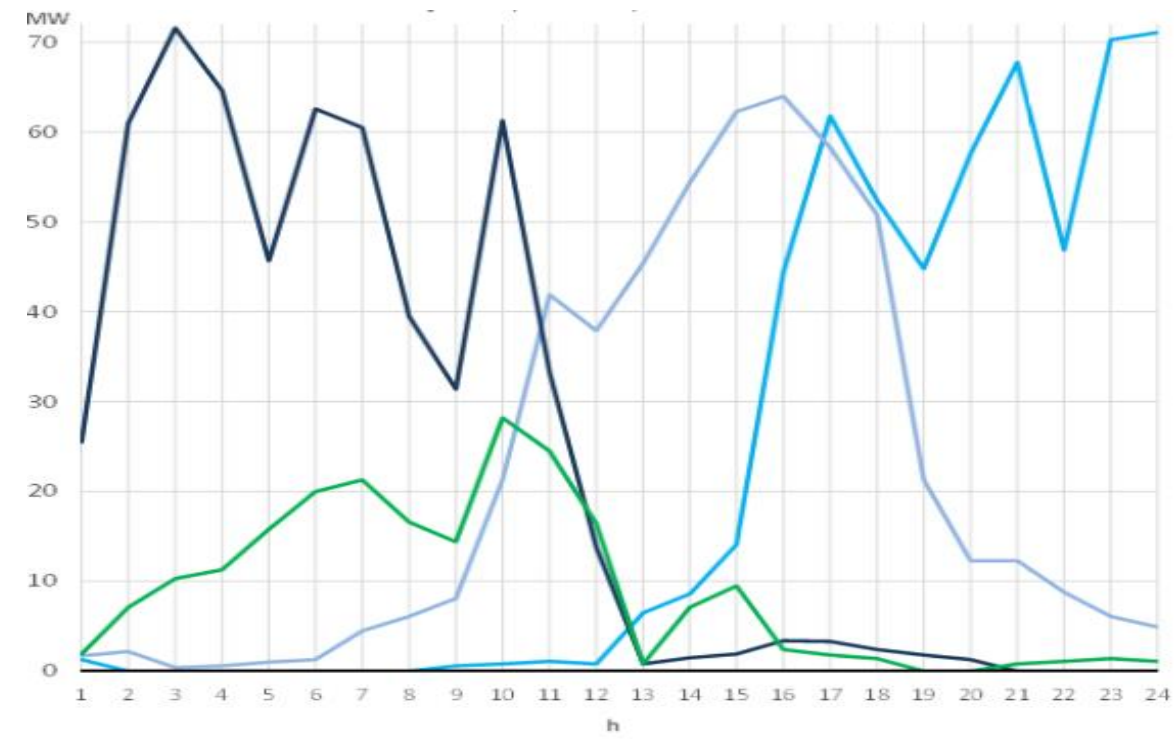

Fig. 2.2. Variations of "Krnovo" output power for a period of one day with little wind [1] 


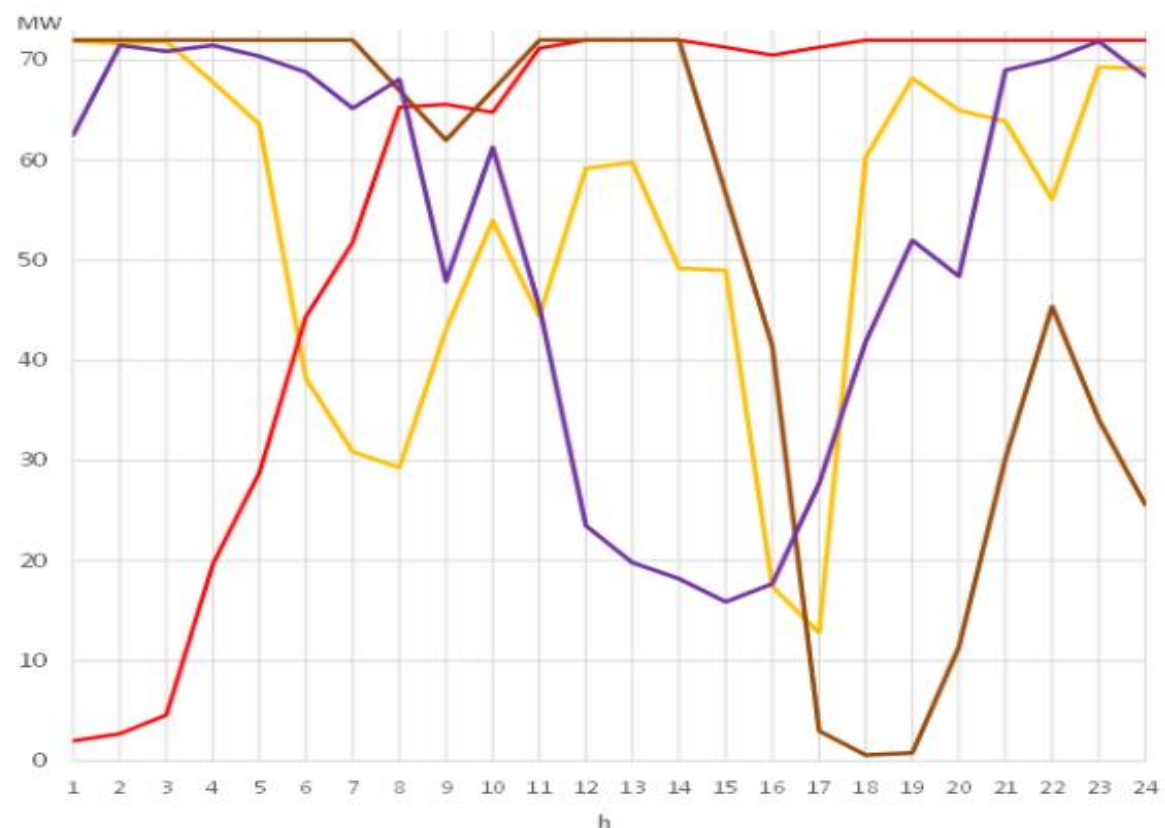

Fig. 2.3. Variations of Krnovo output power for a period of one day with strong wind [1]

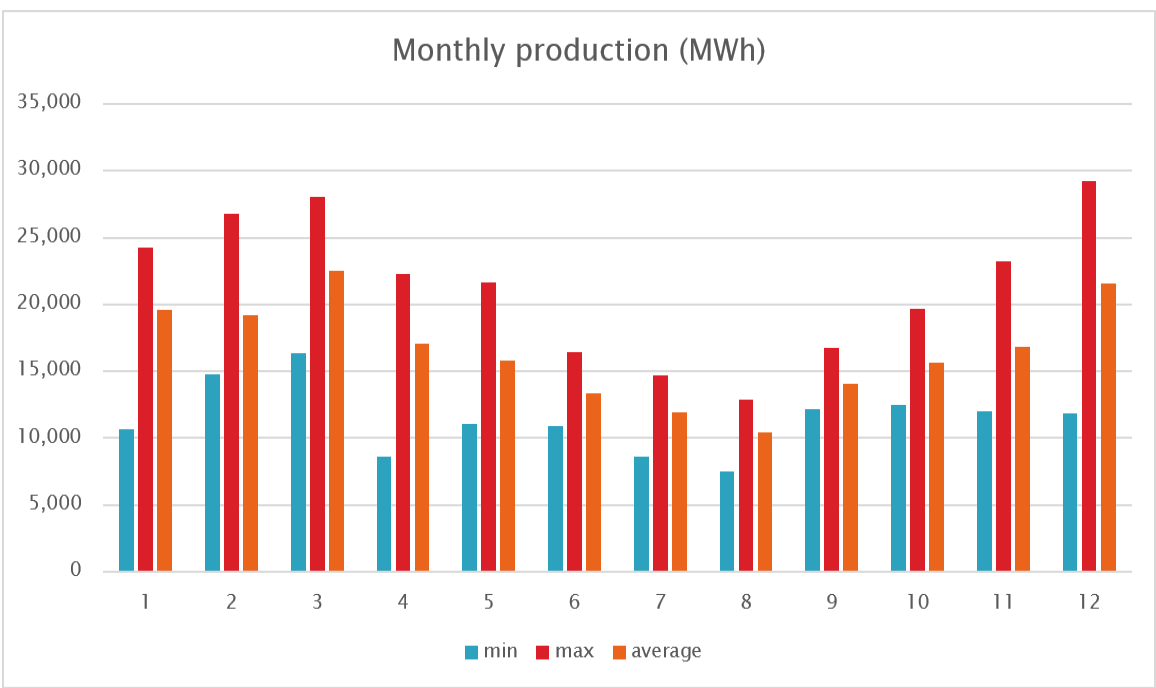

Fig.2.4. Monthly production of Krnovo, obtained on the basis of the trial period of work [1] 
Forecast of the Krnovo production, based on the measurements results during trial work period, presented in Fig. 2.2. and Fig. 2.3. show significant variations in power. Different lines represents the production of Krnovo for 24 hours for different days [1]. In a certain part of the day, Krnovo can achieve high production, while in the second part of the day this production is significantly lower. The total production measured at the monthly level, as shown in Fig. 2.4., shows large deviations between maximum and minimum production in certain months. These informations shows us that big and sudden changes in the wind speed can lead to unstable production of the Krnovo.

Taking these results into account, in order to increase the role of the Krnovo in the Montenegrin power system, this paper proposes connection of the lithium-ion battery energy storage system (Li-ion BESS), with the aim of adjusting the output power of the Krnovo to a more constant value. This type of application of the EES is called capacity firming. EES can modify variations in active power, adjust reactive power and solve problems related to the impossibility of forecasting the change of wind speed for a longer period of time.

The following technical requirements must be met for the connection of the EES at the wind power plant [5]:

1) Long lifetime;

2) High charge/discharge efficiency;

3) Affordable price and payback period;

4) Safety and reliability.

Regarding the above technical requirements, the best results have Li-ion BESS: efficiency around $90 \%$, payback period around 10 years of use [7], lifetime around 4000 cycles [8]. Other features that distinguish the lithium battery in front of the others are power and energy density, large capacity, low self-discharge (around $0.005 \%$ per month [8]), discharge duration, etc.

\section{The Li-ion BESS}

BESS converts electrical into chemical energy during the process of charge, and during discharge it converts chemical to electrical energy and releases it to the system.

BESS is a complex system, which consist of 4 interconnected parts:

1) Storage medium (li-ion battery in this case);

2) Power conversion system (PCS); 
3) Battery management system (BMS);

4) Balance of plant (BOP).

The scheme of the connection of BESS to the power system is presented in Fig. 3.1 .

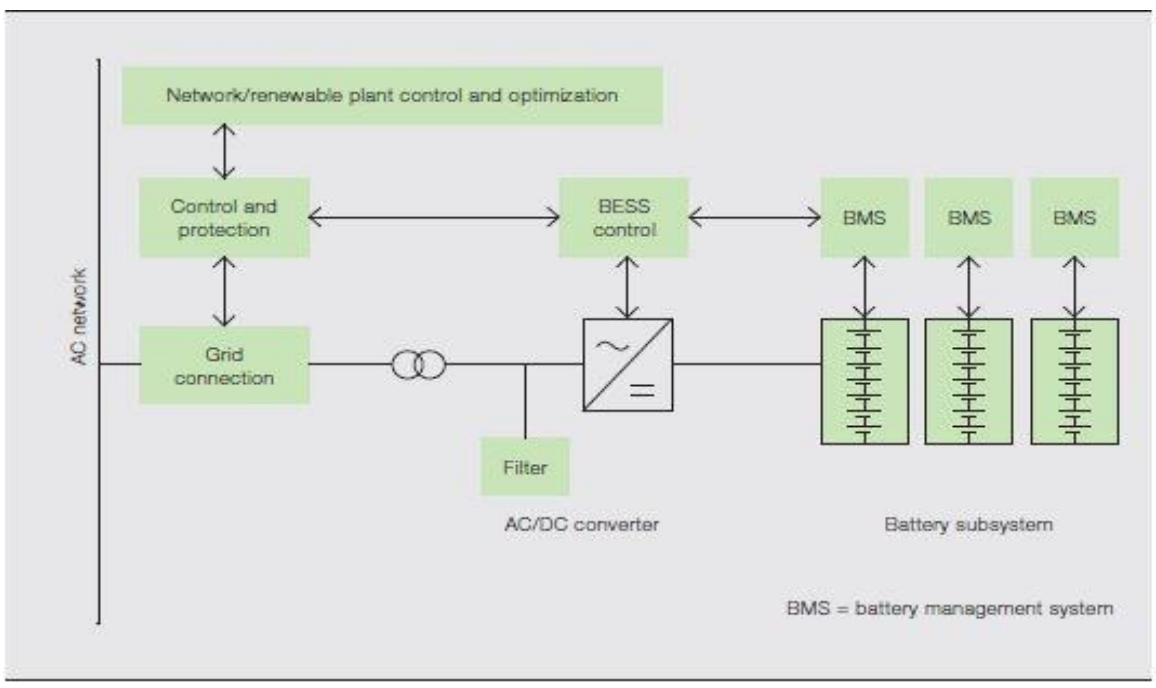

Fig. 3.1. Scheme of the BESS connection [3]

1) Li-ion battery:

The battery cell consist of the following parts: electrodes (cathode ${ }^{+}$and anode), electrolyte, separator and container. Technology of the li-ion batteries is based on the lithium, which has very high reactivity and electrochemical potential, because of which the battery has higher power and energy density over other batteries. Also, lithium is the lightest metal, and because of that fact the li-ion battery has the lowest weight compared to the other types of batteries, which is important advantage. The li-ion battery scheme is shown in the Fig. 3.2.

\section{ANODE}

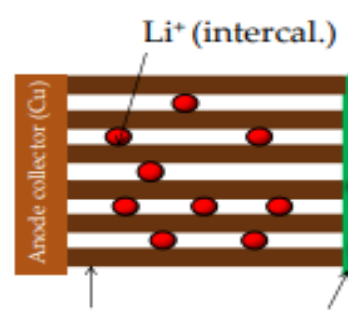

Graphite
CATHODE

$\mathrm{Li}^{+}$(intercal.)

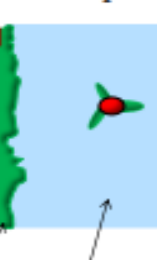

SEI electrolyte

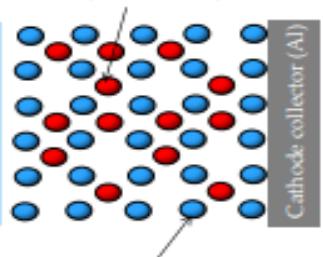

$\mathrm{Li}^{+}$(solvate) Metal-Oxide 
Fig. 3.2. Scheme of the li-ion battery [9]

During the battery process of charge, the anode receives electrons from the cathode through the external circuit (which existence is necessary in the case of li-ion battery) and the $\mathrm{li}^{+}$ions from the cathode are moving through the electrolyte to the anode, so that the whole system is then electrically neutral. Electrolyte serves to transfer $\mathrm{li}^{+}$ions during charge/discharge process. During the battery discharge process, the electrons are released into the external circuit, while the $\mathrm{li}^{+}$ions are moving through the electrolyte back to the cathode. The movement of the $\mathrm{li}^{+}$ions causes the formation of a current flow from the cathode to the anode [2].

2) Power conversion system - PCS:

PCS controls the conversion and power flow for the battery charge/discharge process. The most common PCS solution is buck/boost converter, which adjust the power grid voltage level to the voltage level of the battery system. Another PCS solution is the bi-directional inverter, which is capable to convert DC to AC and opposite.

Another part of the PCS is the low-pass filter, which is used to mitigate the impact of the high frequency harmonics. The most commonly used is LCL filter, connected between each phase [2].

3) Battery management system - BMS:

BMS - control unit that decides in which direction the energy flows, and unit that is responsible for battery operation. It consist of battery control and monitoring system, protection and local MicroSCADA system. Battery control unit must be at high level to avoid excessive charge or discharge of the battery cell. The most important parameters that must be controlled during battery operation are the state of charge (SOC), voltage, current, depth of discharge (DOD) and temperature.

The discharge current have to be strictly controlled at low temperatures, since the internal resistance is increasing and the avaliable capacity and voltage are decreasing drastically. While charging at low temperature, the internal resistance is increasing, which negatively affects the value of the charging current and battery voltage.

During excessive charging process there is a risk of a sudden increase in battery voltage which can lead to the battery damage. Likewise, during excessive discharging process, battery voltage can drop on too low value which can also lead to the battery damage. When the battery voltage is below $2.5 \mathrm{~V}$, the discharge process have to be stopped. During the discharge process, if the SOC drops below $20 \%$ it is more difficult to operate the battery due to the high inconstancy of the voltage and the associated increase of internal resistance [5]. 
SOC, DOD and temperature are the parameters that can have negative impact on the battery life - calendar life and lifetime expectancy (cycle lifetime). As can be seen from the Fig. 3.3., the calendar life (expected life) of the li-ion battery decreases with a higher percentage of the SOC and higher optimum operating temperature. The optimum value of the battery SOC is $50 \%$, with temperature around $20-40^{\circ} \mathrm{C}$. The number of cycles decreases with a higher percentage of the DOD (Fig. 3.4.) [2].

\section{Expected life for VL Li-ion cells according to temperature} (EOL for capacity loss of $20 \%$ )

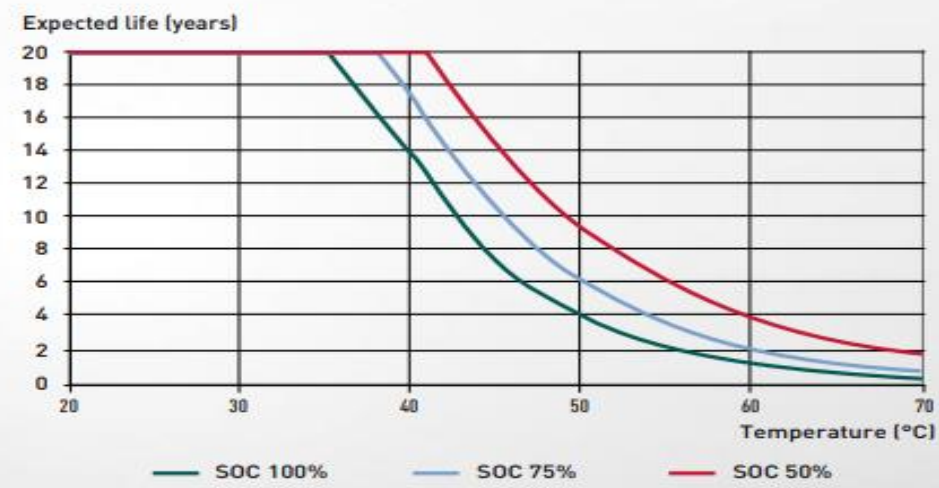

Fig. 3.3. Expected battery life depending on the SOC. EOL - End of life of the battery [4]

$$
\text { Cycle life at }+25^{\circ} \mathrm{C} /+77^{\circ} \mathrm{F}
$$

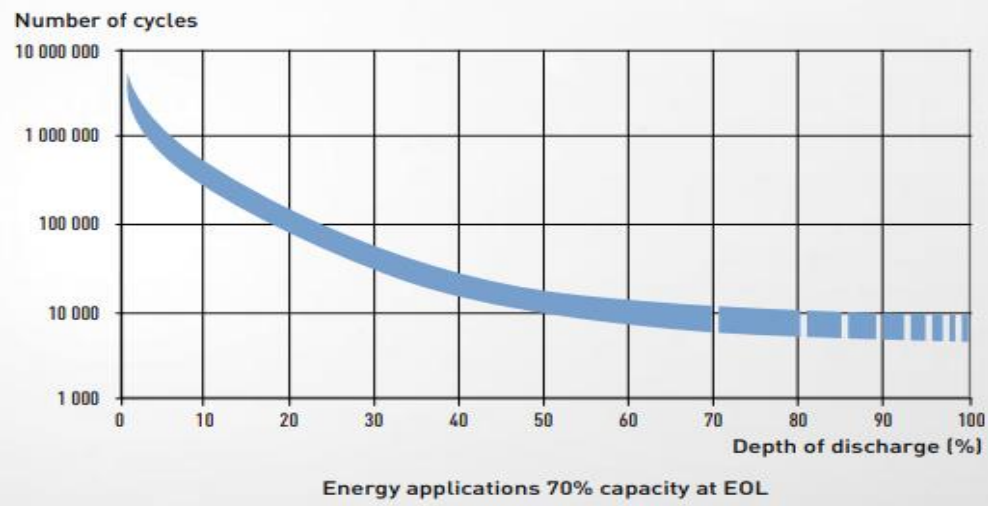

Fig. 3.4. Expected battery cycle depending on the DOD [4] 
Complex control of the SOC and DOD, large safety requirements related to the control of temperature, current and voltage are the disadvantages of the li-ion over other types of batteries.

4) Balance of plant - BOP:

The BOP system consist of transformers, switches, protective equipment, monitoring and other to ensure reliable connection of the BESS to the power plant and reliable operation.

\section{MATLAB Simulink - simulation of the connection of the Li- ion BESS to the Krnovo power plant}

The effect of the Li-ion BESS connection to the Krnovo is analyzed through the simulation performed in the MATLAB Simulink software. The objective is to analyze the influence of the Li-ion BESS on the variable output power of the Krnovo and on the system's voltage stability in the case of wind variations close to the average wind speeds at the Krnovo area. In the simulation, battery system with the capacity of $20 \mathrm{MWh}$ is used.

Krnovo is connected via the $33 / 110 \mathrm{kV}$ substation to the power system of Montenegro, as it is presented in Fig. 4.1. Scheme from Fig. 4.1. is implemented in MATLAB Simulink software, which is presented in Fig. 4.2. Fig. 4.3. presents scheme of the Li-ion BESS setup.

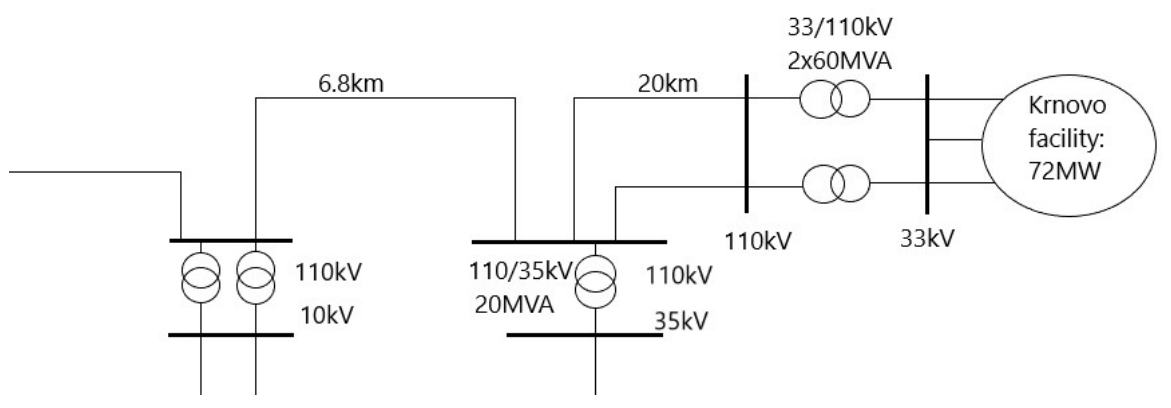

Fig. 4.1. Scheme of connection of the Krnovo wind power plant to the electric power system of Montenegro [1]

The following setup is used for Krnovo:

- Generators rated voltage: $2.85 \mathrm{MW} / 2.5 \mathrm{MW} \quad(20 \times 2.85 \mathrm{MW}+$ $6 \times 2.5 \mathrm{MW})$; 
- Frequency: $50 \mathrm{~Hz}$;

- Power factor: 0.9 ind/cap;

- Cut-in wind speed: $3 \mathrm{~m} / \mathrm{s}$;

- Cut-out speed: $25 \mathrm{~m} / \mathrm{s}$.

The BESS parameters are:

- Total power: $20 \mathrm{MWh}(10 \times 2 \mathrm{MWh})$;

- Initial SOC: 50\%;

- $\quad$ Rated voltage of single battery cell: $12.6 \mathrm{~V}$;

- Battery response time: $5 \mathrm{~s}$;

- PCS: bi-directional inverter + low-pass filter.

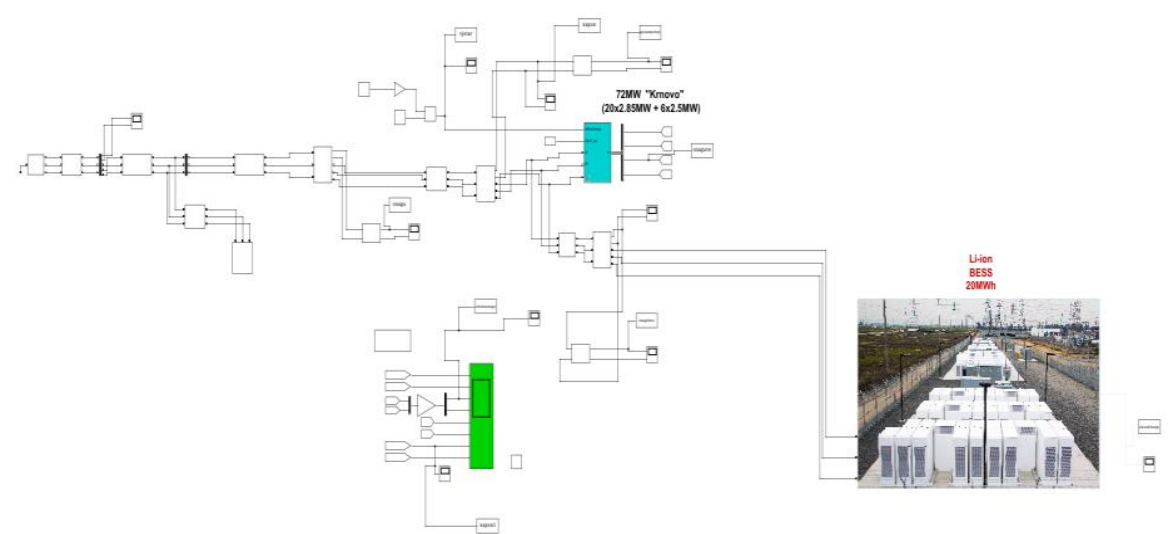

Fig. 4.2. Scheme of the connection of the Li-ion BESS to the Krnovo wind power plant in MATLAB Simulink software

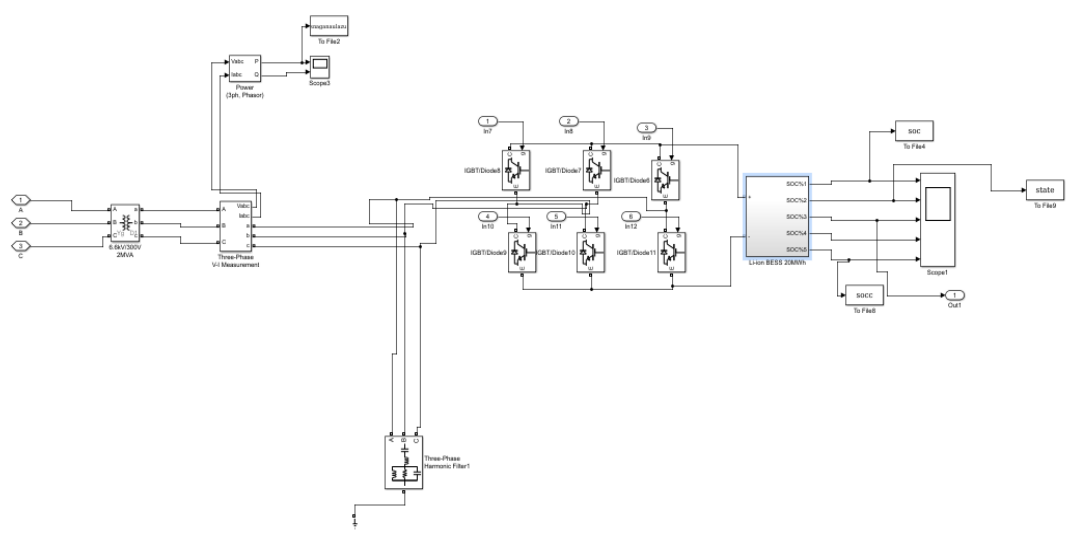

Fig. 4.3. Scheme of the Li-ion BESS in MATLAB Simulink software 
The wind speed variations are set from $4.5 \mathrm{~m} / \mathrm{s}$ to $10.5 \mathrm{~m} / \mathrm{s}$, which is shown in Fig. 4.4. Changes in wind speeds cause variations in Krnovo output power, measured at a connection point of this facility and the power system, with a Li-ion BESS connected, as shown in Fig. 4.5. The output power values are changing from $40 \mathrm{MW}$ to around $30 \mathrm{MW}$, at the very beginning of the simulation (Fig. 4.5.). As the simulation progresses, the value of the output power is stabilized to a value of about 20MW, due to the influence of the Li-ion BESS. This process corresponds to the type of the Li-ion BESS application - capacity firming. As noted earlier, the BESS maintains for a fixed period of time constant output power of the wind power plant at a specified (fixed) level. Also, at the beginning of the simulation, sudden changes in the wind speed cause voltage variations at the location of the Krnovo connection to the system, but it is also stabilized by the influence of the BESS, as shown in Fig. 4.6.

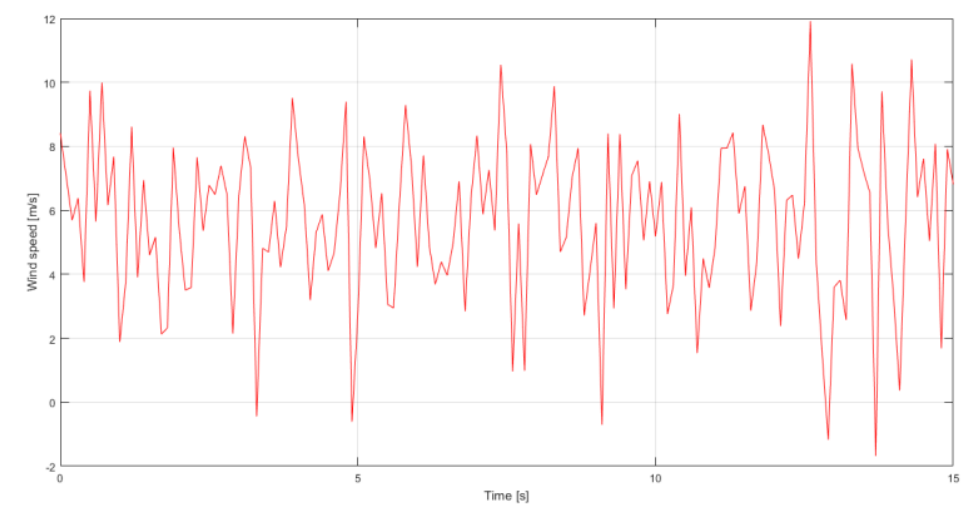

Fig. 4.4. Wind variations at Krnovo during the simulation

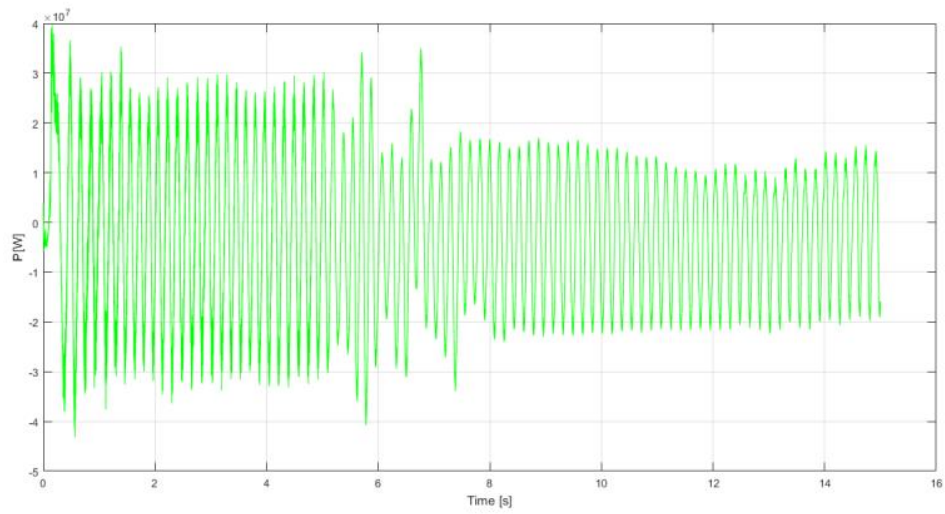


Figure 4.5. Variations of the output power of the wind power plant Krnovo

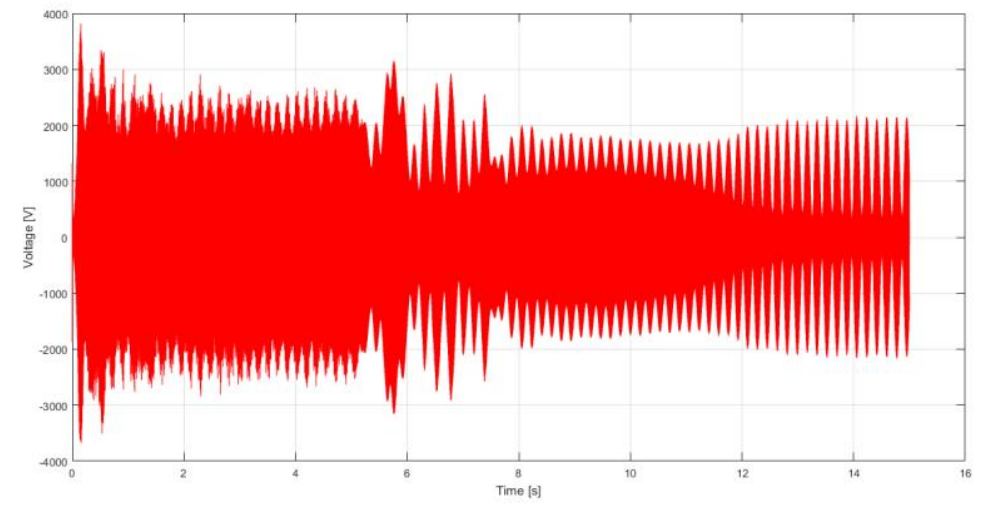

Fig. 4.6. Voltage variations at the point of connection of the Krnovo to the power system

Li-ion BESS, initially set to $50 \%$ SOC, during this simulation operates in the charge mode, and it "accepts" energy during the period of voltage and power output variations, as shown in Fig. 4.7.

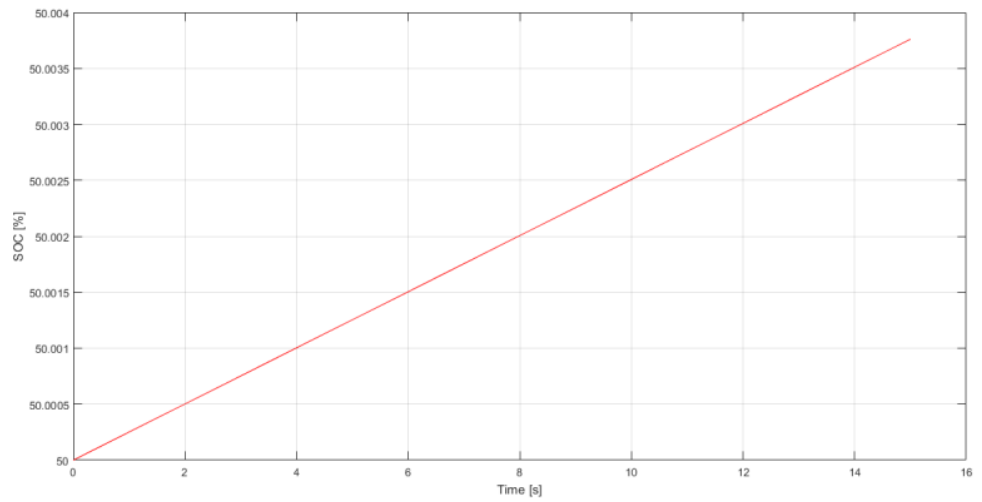

Fig. 4.7. SOC of the single Li-ion cell - Battery system operates in charge mode during the simulation process

Fig. 4.8. represents the variations of power at the point of connection of the one of the Li-ion BESS units of $2 \mathrm{MWh}$. The results from Fig. 4.8. shows that during the highest power variations (shown in Fig. 4.5.), the Li-ion BESS operates in charge mode, i.e. it "takes over" the part of the Krnovo output power in order to maintain it at a more stable value. 


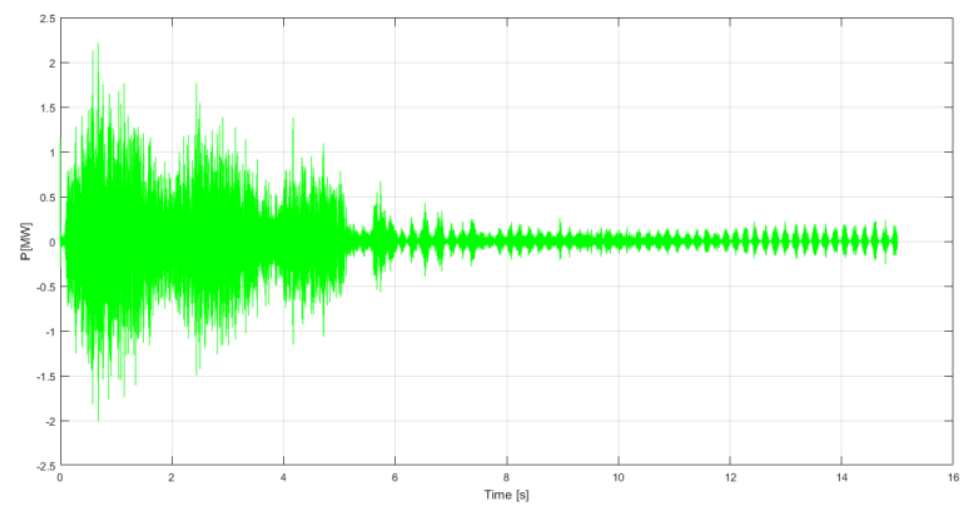

Fig. 4.8. Power variations at the connection point of the Krnovo and the Li-ion BESS unit

In the case of the simulation of the operation of Krnovo facility without the Li-ion BESS, higher variations of power happens: from $40 \mathrm{MW}$ to the $20-30 \mathrm{MW}$, after which the power drops rapidly to around 10-15MW (shown in Fig. 4.9.).

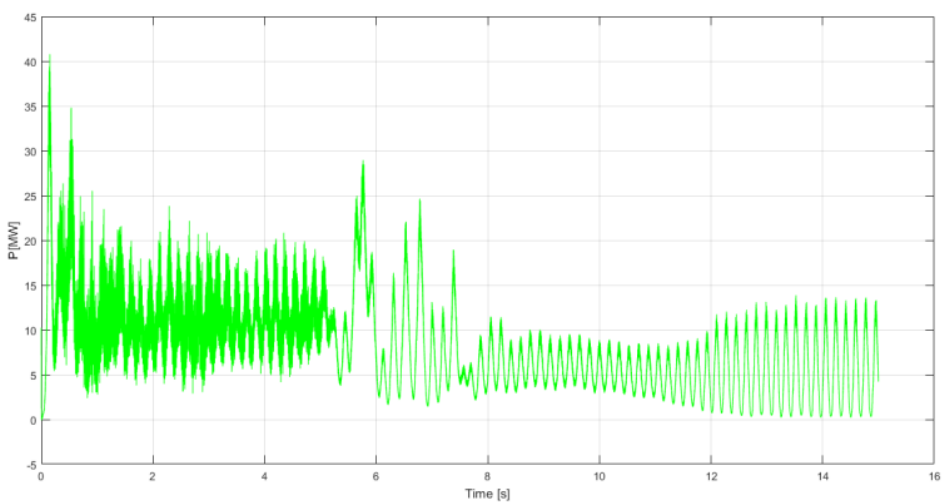

Fig. 4.9. Variations of the output power of the Krnovo without the connection of the Li-ion BESS

Ultimately, the conclusion is that, due to the wind power variations ranging from $4.5 \mathrm{~m} / \mathrm{s}$ to $10.5 \mathrm{~m} / \mathrm{s}$, the result is destabilization of the Krnovo output power, as well as instability of the voltage at the connection point of Krnovo and Montenegrin power system. The power varies in the range of $40 \mathrm{MW}$ to around $30 \mathrm{MW}$.

In order to maintain the stability of the above mentioned values, the Li-ion BESS operates in a charge mode - during huge power variations BESS receives excess of power, and thus controls the Krnovo output power. As a result of Li-ion BESS 
operation, the Krnovo output power is stabilized to around 20MW, and the problem of voltage stability is also solved.

\section{Conclusion}

The Krnovo wind power plant can have a negative impact on the power system of Montenegro, mostly due to its inconsistent and unpredictable production, which significantly decrease its role in the power system of Montenegro.

The results presented in this paper show that the connection of the Li-ion BESS can solve the potential problems that Krnovo can make to the Montenegrin power system by controlling the variable production of the Krnovo power plant at a certain value, making it more stable source of electricity.

\section{Acknowledgment}

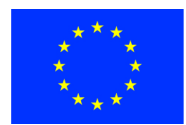

This work was supported by Ministry of Science of Montenegro and European Union's Horizon 2020 research and innovation program under project CROSSBOW - CROSS BOrder management of variable renewable energies and storage units enabling a transnational Wholesale market (Grant No. 773430).

\section{References}

[1] Ranko Goić, Ante Topčić - „Elaborate on testing and compliance of the operation of the Krnovo wind power plant".

[2] Shriram Santhanagopalan, Kandler Smith, Jeremy Neubauer, Gi-Heon Kim, Matthew Keyser, Ahmad Pasaran - „Design and analysis of large lithium-ion battery systems".

[3] ABB - „Energy storage - the benefits beyond the integration of renewables“.

[4] Saft - „Lithium-ion battery life“.

[5] Xiaobin Huang, Beibei Jiang - „Research on lithium battery energy storage system in wind power", 2011 International Conference on Electrical and Control Engineering, IEEE Yichang, China.

[6] Francisko Diaz-Gonzalez, Andreas Sumper, Oriol Gomis-Bellmunt - „Energy storage in power systems", the edition published 2016, pp. 129-220.

[7] Adam Daggett, Meysam Qadrdan, Nick Jenkins - „Feasibility of a Battery Storage System for a Renewable Energy Park Operating with Price Arbitrage“, 
2017 IEEE PES Innovative Smart Grid Technologies Conference Europe (ISGT-Europe).

[8] Enrico Casalini, Sonia Leva - „Feasibility Analysis of Storage Systems in Wind Plants - and Italian Application“, 2017 IEEE International Conference on Environment and Electrical Engineering and 2017 IEEE Industrial and Commercial Power Systems Europe (EEEIC / I\&CPS Europe).

[9] Holger C. Hesse, Michael Schimpe, Daniel Kucevic, Andreas Jossen - „Lithium-Ion Battery Storage for the Grid-A Review of Stationary Battery Storage System Design Tailored for Applications in Modern Power Grids“, Department of Electrical and Computer Engineering, Technical University of Munich (TUM). [10] A.Saez-de-Ibarra, E. Martinez-Laserna, D.I.Stroe, M. Swierczynski, P. Rodriguez - „Sizing Study of Second Life Li-ion Batteries for Enhancing Renewable Energy Grid Integration“, Energy Conversion Congress and Exposition (ECCE), 2015 IEEE.

[11] Željko Tomšić, Ivan Rajšl, Perica Ilak, Matea Filipović - „Optimizing Integration of the new RES generation and Electrical Energy Storage in a Power System: Case Study of Croatia“, 2017 52nd International Universities Power Engineering Conference (UPEC).

[12] Danilo Antonio Sbordone, Biagio Di Pietra, Enrico Bocci - „Energy analysis of a real grid connected lithium battery energy storage system“, avaliable online at www.sciencedirect.com, Published by Elsevier Ltd.

[13] Maryam Bahramipanah, Dimitri Torregrossa, Rachid Cherkaoui, Mario Paolone - „Enhanced Equivalent Electrical Circuit Model of Lithium-Based Batteries Accounting for Charge Redistribution, State-of-Health, and Temperature Effects“", IEEE Transactions on Transportation Electrification ( Volume: 3, Issue: 3, Sept. 2017 ). 